\title{
Neuroprotective Effects of Rutin and Quercetin Flavonoids in Glaucium corniculatum Methanol and Water Extracts
}

\author{
Fatma Gonca KOÇANCI ${ }^{* 1}$, Buket HAMAMCIOĞLU' ${ }^{1}$, Belma ASLIM ${ }^{1}$
}

${ }^{1}$ Gazi University, Faculty of Science, Department of Biology, Ankara

Received: 04 May 2017 - Revised: 09 June 2017 - Accepted: 03 August 2017

\begin{abstract}
Neurodegenerative diseases (NDs) are characterized by loss of neurons. NDs are associated with development of inflammation. Existing drugs against NDs only delay the progression; however, they do not provide a cure. The studies for the treatment of NDs focused on to discover natural products that have the potential of anti-inhibition and anti-radical properties. The Papaveraceae family members are important for the synthesis of pharmaceutically compounds such as flavonoids which act like anti-inflammatory drugs. In this study, methanol and water extracts of Glaucium corniculatum, a member of the Papaveraceae family, were analysed for flavonoid compounds. The effects of extracts on neuronal PC12 cells viability was determined. The anti-inflammatory effects of extracts were assessed by measuring the levels of IL-6 and IL-10 cytokines on hydrogen peroxide $\left(\mathrm{H}_{2} \mathrm{O}_{2}\right)$ stimulated PC12 cells. As a result of our studies, Rutin and Quercetin flavonoids have been found to be as major. The amount of Rutin was higher in methanol $(45 \mu \mathrm{g} / \mathrm{ml})$ than water $(41 \mu \mathrm{g} / \mathrm{ml})$. Quercetin was better extracted with methanol $(12 \mu \mathrm{g} / \mathrm{ml})$ than water $(10 \mu \mathrm{g} / \mathrm{ml})$. None of the tested extracts were cytotoxic even to PC12 cells. Both extracts showed an anti-inflammatory effect in a dose dependent manner. The water extract showed the maximum anti-inflammatory effect, with IL-6 secretion decreased 79 fold according to the $\mathrm{H}_{2} \mathrm{O}_{2}$ treated group and IL-10 secretion increased to 87 fold according to the control group. This study is an evidence that the Rutin and Quercetin flavonoids detected in G. corniculatum methanol and water extracts have a neuroprotective effect through anti-inflammation.
\end{abstract}

Keywords: Glaucium corniculatım, flavonoid, neurodegenerative diseases, anti-inflammation

\section{INTRODUCTION}

Neurodegenerative diseases (NDs) such as Alzheimer's disease (AD), Parkinson's disease (PD), amyotrophic lateral sclerosis (ALS) and multiple sclerosis (MS) are defined as disorders with loss and damages of neurons. Approximately 30 million people worldwide are affected by NDs and it is estimated that until 2040, casualties caused by NDs will be the second after cancer. A common link between these diseases is chronic activation of innate immune responses, also known as inflammation [2]. Inflammation is a response that operates against the endogenous or exogenous agents such as infection, injury, and exposure to contaminants to continue the organism's life. The inflammation response that occurs in chronic conditions is caused the extracellular matrix damages and organ dysfunctions [3]. It has been proven that chronic inflammation is a part of the cause of NDs $[4,5]$. Mechanisms responsible for the perception,

${ }^{*}$ Corresponding Author E-mail: goncaok@gmail.com

ISSN: $2148-6905$ online /C) 2017

DOI: $10.21448 /$ ijsm. 363347 
conduction and replication of inflammatory processes that cause the production of neurotoxic mediators, such as cytokines and interleukins, are associated with NDs [6,7]. The evidences of chronic inflammation in NDs are based on the findings on increased levels of proinflammatory cytokines such as interleukin 6 (IL-6) [8] and deceased levels of anti-inflammatory cytokines such as interleukin 10 (IL-10). Understanding the interaction between the inflammation and nervous systems is crucial as a strategy to intervene with chronic NDs.

There are some drugs approved by U.S. Food and Drug Administration (FDA) such as dopamine agonists, cholinesterase inhibitors, anti-inflammatory medications and calcium channel blockers that are used for the treatment and prevention of NDs [9]. The existing drugs against NDs, only delay the progression of the disease by alleviating the symptoms; however, they do not provide a complete cure.

In recent years, the studies for the discovery of novel drugs and biomarkers for the treatment of NDs focused on strategies to discover natural products that have the potential of anti-inflammatory properties. These studies usually focus on drugs used in traditional medicine, most of which are plant extracts. Plant derived bioactive compounds such as steroidalpiperidine-alkaloids, fatty acids, phenols, alkaloids, saponins, terpenes and flavonoids play a major role in the slowing of many NDs. Some plants have traditionally been used for centuries to treat memory impairment. One of these species is Glaucium corniculatum, belonging to the family of Papaveraceae [10]. The species of the Papaveraceae biosynthesize pharmacologically active flavonoids, known to exhibit different pharmacological effects such as anti-inflammatory and neuroprotective [11]. Rutin (3, 3', 4', 5, 7-pentahydroxyflavone-3rhamnoglucoside) and Quercetin (3, 30, 40, 5, 7-pentahydroxyflavone) are bioflavonoids of the flavonol type abundantly present in Papaveraceae. Many studies have been carried out to understand the medicinal importance of Rutin and Quercetin. They have been reported to exert numerous biochemical and pharmacological activities, such as the suppression of cellular immune and inflammatory [12] and neuroprotective [13] responses.

The goal of this study is to thoroughly examine the flavonoid content of methanol and water extracts of Glaucium corniculatum by high-performance liquid chromatography (HPLC) method. However, this study involved testing the ability of these extracts to protect differentiated PC12 (dPC12) cells by nerve growth factor (NGF) from neuroinflammation and neurodegeneration when exposed to neurotoxic insult induced by $\mathrm{H}_{2} \mathrm{O}_{2}$ as an in vitro model, by analyzing the effect of on IL-6 and IL-10 production.

\section{MATERIAL and METHODS}

\subsection{Plant Material}

Crube plants were collected and verified by Prof. Dr. Zeki Aytaç (Gazi University, Faculty of Science, Department of Biology). The voucher specimen was kept in the Herbarium of Gazi University, Faculty of Science, Department of Biology. G. corniculatum (L.) RUD. subsp. refractum (NAB.) CULLEN was collected from Beypazari district in the northwest of Ankara on 9.07.2012.

\subsection{Preparation of Plant Extracts}

Above-ground tissues of the plant samples were dried, powdered with an electric grinder and stored in laboratories of the Faculty of Science Department of Biology, Gazi University, Turkey. The plant powder ( 30 gr) were macerated with $300 \mathrm{~mL}$ of methanol and water, respectively at the room temperature for 6 hours using soxhlet device (LabHeat). The extracts were filtered by whatman filter paper and evaporated to dryness $\left(45^{\circ} \mathrm{C}\right)$ under reduced pressure by rotary evaporator (Heidolph Laborota 4000) and stored in a refrigerator at $4^{\circ} \mathrm{C}$ until the time of use [14]. 


\subsection{Quantitative HPLC Analysis of Flavonoids in Plant Extracts}

Flavonoids in the samples were identified on an Agilent Technologies HPLC 1200 series (Santa Clara, CA, USA) equipped with a quaternary pump, a manual sampler and an ultraviolet/ visible (UV-Vis) detector with a loop size of $20 \mu \mathrm{l}$. The reversephase chromatographic analysis was carried out in isocratic conditions using a C-18 reverse phase column $(150 \mathrm{~mm} \times 4.6 \mathrm{~mm}$ i.d., particle size $5 \mu \mathrm{m}$, Agilent Zorbax Eclipse XDB-C18) at $25^{\circ} \mathrm{C}$. Simultaneous monitoring was performed at $254 \mathrm{~nm}$ and $330 \mathrm{~nm}$ and a flow rate of $1 \mathrm{~mL} / \mathrm{min}$. The amount of each phenolic compound was expressed as $\mu \mathrm{g}$ per mg of the extracts [15].

\subsection{PC12 Cell Culture}

Pheochromocytoma PC12 cells were obtained from Gazi University, Biotechnology Laboratory Collection and they were maintained in Dulbecco's modified Eagle's medium (DMEM) supplemented with 10\% fetal bovine serum (FBS), 10\% horse serum (HS), 1\% antibiotic mixture comprising penicilin streptomycin $(100$ units $/ \mathrm{mL}$ penicilin- $100 \mu \mathrm{g} / \mathrm{mL}$ streptomycin) and $1 \%(2 \mathrm{mM}) \mathrm{L}$-glutamine in a humidified $\mathrm{CO}_{2}(5 \%)$ incubator at $37^{\circ} \mathrm{C}$. The medium was changed every other day. The cells were differentiated for 4 days using $100 \mathrm{ng} / \mathrm{mL}$ NGF [16]. The differentiation medium was refreshed every two days.

\subsection{Cell Viability Assay}

In order to determine the toxicity of $\mathrm{H}_{2} \mathrm{O}_{2}$, the cells were plated at an appropriate density $\left(1 \times 10^{4}\right.$ cells $\left./ 200 \mu \mathrm{L}\right)$ in a collagen-coated $96-$ well plate. After that, the cells were treated with $200 \mu \mathrm{M} \mathrm{H}_{2} \mathrm{O}_{2}$ for 12 and $24 \mathrm{~h}$.

To determine the toxicity of $G$. corniculatum extracts, the cells were plated at an appropriate density $\left(1 \times 10^{4}\right.$ cells $\left./ 200 \mu \mathrm{L}\right)$ in a collagen-coated 96 -well plate at $37^{\circ} \mathrm{C}$ in $95 \%$ humidified air with $5 \% \mathrm{CO}_{2}$. dPC12 cells were treated with $100,250,500$ and $1000 \mu \mathrm{g} / \mathrm{ml}$ plant extracts which were diluted with differentiation medium for 12 and $24 \mathrm{~h}$. The cell viability was assessed by 3-[4,5-dimethylthiazol-2-yl]-2,5-diphenyltetrazolium (MTT) assay. After incubation, to each well $20 \mu \mathrm{l}$ of MTT $(5 \mathrm{mg} / \mathrm{ml})$ in phosphate buffered saline (PBS) was added and incubated at $37^{\circ} \mathrm{C}$ for $4 \mathrm{~h}$. MTT medium was carefully aspirated from the wells and the formed formazan crystals were solubilized in $200 \mu \mathrm{l}$ of dimethyl sulfoxide (DMSO). Using a micro plate reader the absorbance was measured at $570 \mathrm{~nm}$ (Epoch, BioTek) [17]. The \% cell viability was determined using the following formula:

$\%$ Cell Viability $=[$ Abs $($ sample $) /$ Abs (control) $] \times 100$ [18].

\subsection{Anti-inflammatory Effect of Extracts}

Interleukin-10 (RT IL-10-Life Tech. (KRC0101)) and Interleukin-6 (RT IL-6-Life Tech. (KRC0061)) ELISA kits were used to test the anti-inflammatory effect of the extracts. The cells were seeded in 96-well plates $\left(1 \times 10^{4}\right.$ cells per well) and pretreated with $100,250,500 \mu \mathrm{g} / \mathrm{ml}$ for $24 \mathrm{~h}$ prior to exposure to $200 \mu \mathrm{M} \mathrm{H}_{2} \mathrm{O}_{2}$. After $24 \mathrm{~h}$, the cell culture media was collected. The IL-10 and IL- 6 levels in cell culture mediums of the samples and control groups were measured using IL-10 and IL-6 commercial kits according to the manufacturer's instruction. In each assay, the duplicates of each sample, standard, and blank control (zero standard) were run on the same microplate. Furthermore, IL-10 and IL-6 levels were expressed in pg/mL of the cell culture medium [19].

\subsection{Statiscal Analysis}

The analysis of the data was performed by analysis of variance (ANOVA) followed by Tukey's post-test to test for significance, which was set at 5\%. The results were presented as mean value \pm standard deviation ( $\mathrm{n}=5$ for the MTT assays, $\mathrm{n}=3$ for all other analysis). 


\section{RESULTS and DISCUSSIONS}

\subsection{Qualitative Flavonoid Analysis}

The identification of the individual flavonoids was performed through HPLC, by comparing their masses and $\lambda \max$ with the literature data (Table 1). Rutin and Quercetin were indentified, but Luteolin, Biochanin, Kaemferol, Genistein, Catechin and Apigenin could not be identified (Ni) in methanol extract. Luteolin, Rutin and Quercetin were indentified, but Biochanin, Kaemferol, Genistein, Catechin and Apigenin could not be identified in the water extract. As a result of our studies, Rutin and Quercetin flavonoids were found as major and the other flavonoid contents were insignificant. The amount of the Rutin was higher in methanol $(45 \mu \mathrm{g} / \mathrm{ml})$ than in water $(41 \mu \mathrm{g} / \mathrm{ml})$. Quercetin was also better extracted with methanol (12 $\mu \mathrm{g} / \mathrm{ml})$ than with water $(10 \mu \mathrm{g} / \mathrm{ml})$.

Table 1. Quantitative analysis of flavonoids in G. corniculatum methanol and water extracts

\begin{tabular}{|c|c|c|c|c|c|c|c|c|}
\hline \multirow[t]{2}{*}{ Extracts } & \multicolumn{8}{|c|}{ Flavonoids $(\mu \mathrm{g} / \mathrm{ml})$} \\
\hline & Luteolin & Biochanin & Rutin & Quercetin & Kaemferol & Genistein & Catechin & Apigenin \\
\hline Methanol & $\mathrm{Ni}$ & $\mathrm{Ni}$ & 45 & 12 & $\mathrm{Ni}$ & $\mathrm{Ni}$ & $\mathrm{Ni}$ & $\mathrm{Ni}$ \\
\hline Water & 0.23 & $\mathrm{Ni}$ & 41 & 10 & $\mathrm{Ni}$ & $\mathrm{Ni}$ & $\mathrm{Ni}$ & $\mathrm{Ni}$ \\
\hline
\end{tabular}

\subsection{Effects of $\mathrm{H} 2 \mathrm{O} 2$ on viability of dPC12}

In our assays, $\mathrm{H}_{2} \mathrm{O}_{2}$ did not show any significant cytotoxic effects at $100 \mu \mathrm{M}$ concentrations for 12 and $24 \mathrm{~h}$ (data not shown). Therefore, the $200 \mu \mathrm{M}$ concentrations of $\mathrm{H}_{2} \mathrm{O}_{2}$ were used for $24 \mathrm{~h}$ in the subsequent experiments.

\subsection{Effects of G. corniculatum extracts on viability of dPC12}

In our assays, generally, all the extracts were found to have high IC50 values than $1000 \mu \mathrm{g} / \mathrm{ml} \mathrm{IC50}$ concentrations $(1287 \pm 7 \mu \mathrm{g} / \mathrm{mL}$ for methanol and $1150 \pm 8 \mu \mathrm{g} / \mathrm{mL}$ for water) for 24h. The results of cell viability were presented in Table 2. According to the U.S. NCI plant screening program, a crude extract is generally considered to have in vitro cytotoxic activity with an IC50 value $\leq 20 \mu \mathrm{g} / \mathrm{mL}$ [20]. Consequently, all the extracts demonstrated less toxicity on PC12 cells. These results have proven that the extracts do not cause anti-inflammatory effect resulting from cell death in PC12 cells.

Table 2. The effect of G. corniculatum methanol and water extracts on cell viability of PC12

\begin{tabular}{llll}
\hline \multirow{2}{*}{ Extracts } & \multicolumn{2}{l}{ Cell Survival $\left(\mathbf{I C}_{\mathbf{5 0}}\right)(\boldsymbol{\mu g} / \mathbf{m l})$} & \\
Methanol & & $\mathbf{1 2}$ hour & $\mathbf{2 4}$ hour \\
Water & $1650 \pm 5$ & $1287 \pm 7$ \\
\hline
\end{tabular}

Values expressed as mean \pm SD.

\subsection{Anti-inflammatory effects of G. corniculatum extracts}

For the determination of anti-inflammatory effects of the plant extracts, IL-6 and IL-10 were measured in dPC12 cells pretreated with $100,250,500 \mu \mathrm{g} / \mathrm{ml}$ for $24 \mathrm{~h}$ plant extracts prior to exposure to $200 \mu \mathrm{M} \mathrm{H}_{2} \mathrm{O}_{2}$ (As shown in Figure 1 and 2).

The results showed that the extracts $(100,250,500 \mu \mathrm{g} / \mathrm{mL})$ significantly $(\mathrm{P}<0,05)$ inhibited IL- 6 secretion by $\mathrm{H}_{2} \mathrm{O}_{2}$-stimulated dPC12 cells and increased anti-inflammatory cytokine IL-10 secretion in a dose-dependent manner. 
However, dPC12 cells which were treated with $200 \mu \mathrm{M} \mathrm{H}_{2} \mathrm{O}_{2}$ for 24 hours showed a significant increase in the secretion of IL-6 $(1106 \pm 2 \mathrm{pg} / \mathrm{ml})$ when compared to the control $(27 \pm 3$ $\mathrm{pg} / \mathrm{ml})$. Although there was no significant difference between water and methanol extract, the water extract showed the maximum anti-inflammatory effect. The water extract decreased IL6 secretion 79 fold according to the $\mathrm{H}_{2} \mathrm{O}_{2}$ treated group for $500 \mu \mathrm{g} / \mathrm{ml}$ for the highest applied plant extract dose.

In our study, IL-10 levels were found to be $21 \pm 3 \mathrm{pg} / \mathrm{ml}$ in the control group (untreated dPC12 cells). The secretion of IL-10 in G. corniculatum methanol extract treated dPC12 cells was found as $1173 \pm 3,1401 \pm 5 \mathrm{pg} / \mathrm{ml} 1810 \pm 4 \mathrm{pg} / \mathrm{ml}$ and in G. corniculatum water extract treated dPC12 cells as $1224 \pm 51472 \pm 31845 \pm 4 \mathrm{pg} / \mathrm{ml}$, respectively 100,250 and $500 \mu \mathrm{g} / \mathrm{ml}$. Treatment with $G$. corniculatum water extract showed the maximum anti-inflammatory effect with increased IL-10 by 87 fold according to the control group for $500 \mu \mathrm{g} / \mathrm{ml}$, for the highest applied plant extract dose.

Our results suggested that $G$. corniculatum methanol and water extracts exhibited an antiinflammatory effect against $\mathrm{H}_{2} \mathrm{O}_{2}$-induced inflammation of dPC12 cells via increasing antiinflammatory cytokine IL-10 and decreasing pro-inflammatory cytokine IL-6 secretions.

Linear regression analysis proved that the amount of flavonoid and anti-inflammatory activity showed a negative correlation with extract type. Therefore, the inhibition of the inflammation by the extracts may be partially due to the amount of their flavonoid content but might be attributed to the diversification of flavonoid types.

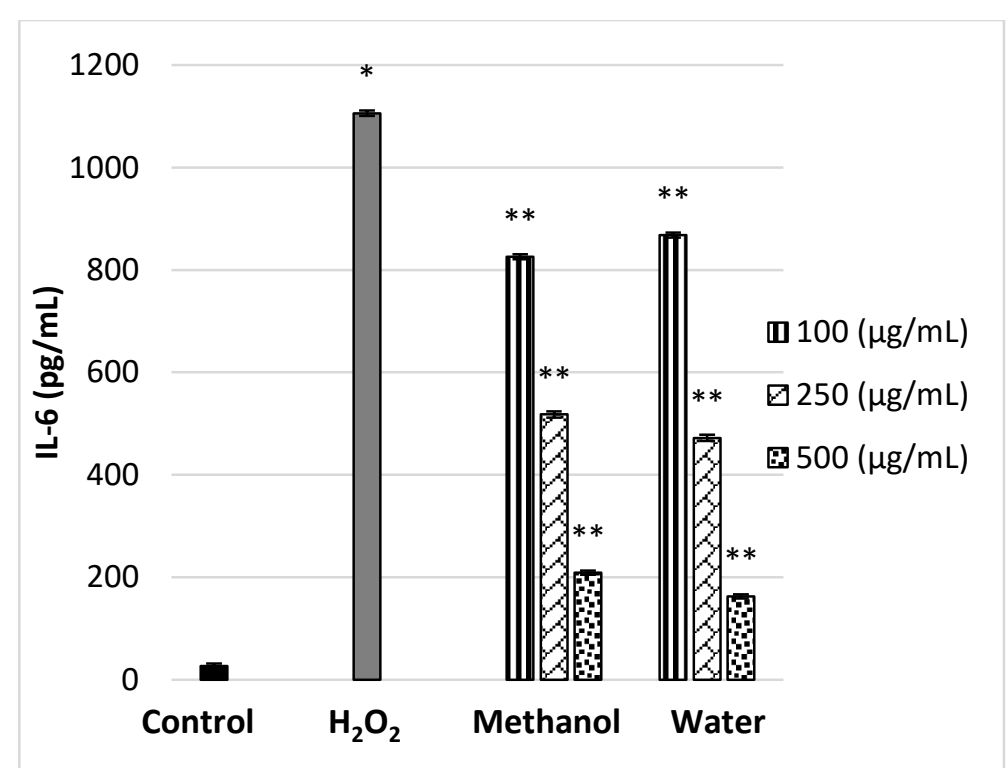

Figure 1. Dose-dependent inhibition of $\mathrm{H}_{2} \mathrm{O}_{2}$ mediated production of IL-6 by G. corniculatum methanol and water extracts in $\mathrm{dPC} 12$ cells. ${ }^{*} \mathrm{p}<0,05$; statistically different compared to negative control (untreated cells). ${ }^{* *} \mathrm{p}<0,05$; statistically different compared to $\mathrm{H}_{2} \mathrm{O}_{2}$ treated group. 


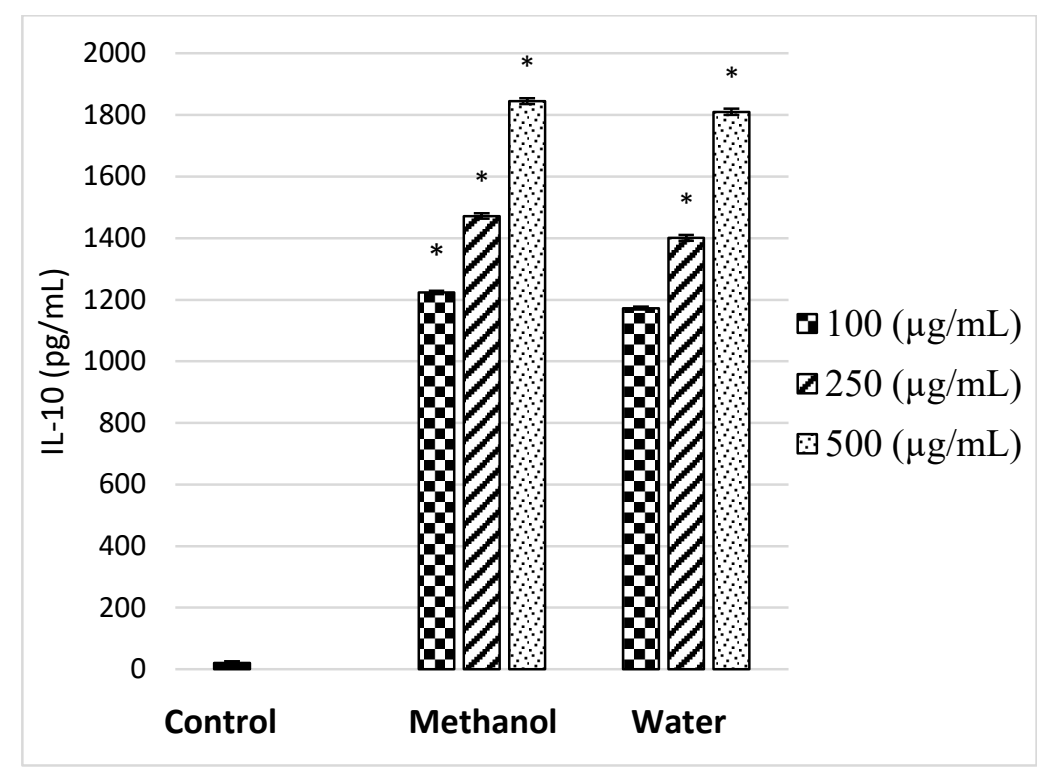

Figure 1. Dose-dependent inhibition of IL-10 TNF- $\alpha$ by G. corniculatum methanol and water extracts in PC12 cells. "p $<0,05$; statistically different compared to the control (untreated cells).

\section{DISCUSSION}

Glaucium-derived products have been used in traditional medicine in the treatment various inflammatory diseases. However, only limited numbers of studies have been conducted to elucidate the action mechanisms of these products on inflammatory diseases [21-23].

Oxidative stress due to the imbalance between ROS and antioxidant defenses will lead to the activation of survival pathway that involves in inflammation. $\mathrm{H}_{2} \mathrm{O}_{2}$ was thought to be the major precursor of reactive free radicals [24]. $\mathrm{H}_{2} \mathrm{O}_{2}$ activated macrophages and stimulated the production of pro-inflammatory cytokines such as IL-1, IL-6, TNF- $\alpha$, leukotrienes, and nitric oxide (NO) [25]. It is known that NDs are associated with neuronal loss, triggered by neurodegenerative agents leading to oxidative stress and the development of inflammation. The levels of IL-6 are normally low and tightly regulated in a cell, but elevated levels of IL- 6 have also been associated with various neurological disorders, including AD, PD, ALS and HD [2628].

The anti-inflammatory effects of $G$. corniculatum methanol and water extracts were assessed here by measuring the expression and the release of pro-inflammatory cytokine IL- 6 and the anti-inflammatory cytokine IL-10. However, in this article, the effects of $G$. corniculatum flavonoids in the suppression of inflammation and the preservation of neurons were investigated. In recent years, various herbal extracts and phytochemicals have been found to have anti-inflammatory properties. For instance, several flavonoids, such as Rutin and Quercetin were found to block IL-6 production [29, 30]. It has been found that flavonoids activate the endogenous antioxidant status in neuronal cells hence protecting them from undergoing neurodegeneration [31]. Polyphenols such as Quercetin and Rutin have distinct features in upregulating the production of intracellular antioxidant enzymes induced in PC-12 cells [32-34]. However, it has been reported that Quercetin and Rutin flavonoids produced antiinflammatory effects by inhibiting proinflammatory cytokines [36, 36]. Hu et al. demonstrated that Rutin ameliorates inflammasome activation, leading to suppressed inflammation in the kidney of rats [37]. Similarly, Javed et al. reported the activity of Rutin in preventing cognitive impairments in rats [38].

The results show that $G$. corniculatum methanol and water extracts inhibit the $\mathrm{H}_{2} \mathrm{O}_{2}$ induced IL- 6 production and increased the production of IL-10 in dPC12 cells. Previous studies 
have shown an antagonist effect of IL-10 on secretion of pro-inflammatory cytokines, suggesting that $G$. corniculatum extract mediated inhibition of the $\mathrm{H}_{2} \mathrm{O}_{2}$ induced IL-6 secretion may pass through the induction of IL-10 production. These outcomes were consistent with the results of anti-inflammatory properties; however, the amount of flavonoids showed a negative correlation with extract type. Therefore, the results suggest that anti-inflammatory effect may be related to flavovoid diversity rather than flavonoid amounts. The ability of $G$. corniculatum extract to modulate the pro-inflammatory and anti-inflammatory cytokines suggests that it may be an alternative agent for the treatment and / or prevention of inflammatory diseases and NDs.

\section{CONCLUSSION}

The amount of flavonoid content of methanol and water extracts of G. corniculatum was successfully screened. Rutin and Quercetin flavonoids are major flavonoids and $G$. corniculatum methanol extract has the highest flavonoid amount.

All of the Glaucium extracts used in this study provide anti-inflammatory effect without damaging dPC12 cells. These results bring attention to the inhibitory effects of G. corniculatum on inflammation and can explain why this plant is considered as a traditional medicinal plant. According to these results, $G$. corniculatum extracts may have a favourable pharmacological profile in the treatment of NDs and inflammation. Moreover, this study proves that the Rutin and Quercetin flavonoids detected in G. corniculatum methanol and water extracts have a neuroprotective effect through anti-inflammation.

\section{Acknowledgement}

The authors thank to Gazi University Scientific Research Projects Unit for funding of this project in part (No. 05/2015-15).

\section{Conflict of Interests}

Authors declare that there is no conflict of interests.

\section{REFERENCES}

[1] Prince, M., Wimo, A., Guerchet, M., Ali, G. C., Wu, Y. T., \& Prina, M. (2000). The global impact of dementia. In Rev Resúmenes World Alzheimer Congress Washington DC (pp. 79-81).

[2] Amor, S., Peferoen, L. A., Vogel, D., Breur, M., Valk, P., Baker, D., \& Noort, J. M. (2014). Inflammation in neurodegenerative diseases-an update. Immunology, 142(2), 151-166.

[3] Sentürk, N. (2013). Kütanöz inflamasyon/Cutaneous inflammation. Turkderm, 47(1), 28.

[4] Gonzalez-Scarano, F., \& Baltuch, G. (1999). Microglia as mediators of inflammatory and degenerative diseases. Annual review of neuroscience, 22(1), 219-240.

[5] Block, M. L., Zecca, L., \& Hong, J. S. (2007). Microglia-mediated neurotoxicity: uncovering the molecular mechanisms. Nature Reviews Neuroscience, 8(1), 57-69.

[6] Glass, C. K., Saijo, K., Winner, B., Marchetto, M. C., \& Gage, F. H. (2010). Mechanisms underlying inflammation in neurodegeneration. Cell, 140(6), 918-934.

[7] Teeling, J. L., \& Perry, V. H. (2009). Systemic infection and inflammation in acute CNS injury and chronic neurodegeneration: underlying mechanisms. Neuroscience, 158(3), 1062-1073.

[8] Silva, A. R., Pinheiro, A. M., Souza, C. D. S., Freitas, S. B., Vasconcellos, V., Freire, S. M., \& Costa, S. L. (2008). The flavonoid rutin induces astrocyte and microglia activation and regulates TNF-alpha and NO release in primary glial cell cultures. Cell Biology and Toxicology, 24(1), 75-86. 
[9] Lleo, A., Greenberg, S. M., \& Growdon, J. H. (2006). Current pharmacotherapy for Alzheimer's disease. Annu. Rev. Med., 57, 513-533.

[10] Ahmed, F., Ghalib, R. M., Sasikala, P., \& Ahmed, K. M. (2013). Cholinesterase inhibitors from botanicals. Pharmacognosy reviews, 7(14), 121.

[11] Saleh, N. A., Maksoud, S. A., El-hadidi, M. N., \& Amer, W. M. (1987). A comparative study of flavonoids in some members of the Papaveraceae. Biochemical systematics and ecology, 15(6), 673-675.

[12] Doyle, S. L., \& O’Neill, L. A. (2006). Toll-like receptors: from the discovery of NFkB to new insights into transcriptional regulations in innate immunity. Biochemical pharmacology, 72(9), 1102-1113.

[13] Katsube, T., Imawaka, N., Kawano, Y., Yamazaki, Y., Shiwaku, K., \& Yamane, Y. (2006). Antioxidant flavonol glycosides in mulberry (Morus alba L.) leaves isolated based on LDL antioxidant activity. Food chemistry, 97(1), 25-31.

[14] Alamdary, S. Z., Khodagholi, F., Shaerzadeh, F., Ansari, N., Sonboli, A., \& Tusi, S. K. (2012). S. choloroleuca, S. mirzayanii and S. santolinifolia protect PC12 cells from H2O2induced apoptosis by blocking the intrinsic pathway. Cytotechnology, 64(4), 403-419.

[15] Oke-Altuntas, F., Aslim, B., Duman, H., Gulpinar, A. R., \& Kartal, M. (2015). The Relative Contributions of Chlorogenic Acid and Rutin to Antioxidant Activities of Two Endemic Prangos (Umbelliferae) Species (P. heynia and P. denticulata). Journal of Food Biochemistry, 39(4), 409-416.

[16] Jacovina, A. T., Zhong, F., Khazanova, E., Lev, E., Deora, A. B., \& Hajjar, K. A. (2001). Neuritogenesis and the nerve growth factor-induced differentiation of PC-12 cells requires annexin II-mediated plasmin generation. Journal of Biological Chemistry, 276(52), 4935049358.

[17] Mosmann, T. (1983). Rapid colorimetric assay for cellular growth and survival: application to proliferation and cytotoxicity assays. Journal of immunological methods, 65(1-2), 55-63.

[18] Zhang, P., Guo, Z., Wu, Y., Hu, R., Du, J., He, X., ... \& Zhu, X. (2015). Histone deacetylase inhibitors inhibit the proliferation of gallbladder carcinoma cells by suppressing AKT/mTOR signaling. PloS one, 10(8), e0136193.

[19] Sorokulova, I., Globa, L., Pustovyy, O., \& Vodyanoy, V. (2016). Prevention of Heat Stress Adverse Effects in Rats by Bacillus subtilis Strain. JoVE (Journal of Visualized Experiments), (113), e54122-e54122.

[20] Sriwiriyajan, S., Ninpesh, T., Sukpondma, Y., Nasomyon, T., \& Graidist, P. (2014). Cytotoxicity screening of plants of genus piper in breast cancer cell lines. Tropical Journal of Pharmaceutical Research, 13(6), 921-928.

[21] Morteza-Semnani, K., Saeedi, M., \& Hamidian, M. (2004). Anti-inflammatory and analgesic activity of the topical preparation of Glaucium grandiflorum. Fitoterapia, 75(2), 123-129.

[22] Arafa, A. M., Mohamed, M. E. S., Eldahmy, S. I. (2016) The Aerial Parts of Yellow Horn Poppy (Glaucium flavum Cr.) growing in Egypt:Isoquinoline Alkaloids and Biological Activities. J. Pharm. Sci. \& Res. 8(5), 323-332.

[23] Pinto, L., Borrelli, F., Bombardelli, E., Cristoni, A., \& Capasso, F. (1998). Antiinflammatory, Analgesic and Antipyretic Effects of Glaucine in Rats and Mice. Pharmacy and Pharmacology Communications, 4(10), 502-505. 
[24] Alia, M., Ramos, S., Mateos, R., Bravo, L., \& Goya, L. (2005). Response of the antioxidant defense system to tert-butyl hydroperoxide and hydrogen peroxide in a human hepatoma cell line (HepG2). Journal of biochemical and molecular toxicology, 19(2), 119-128.

[25] Frossi, B., De Carli, M., Daniel, K. C., Rivera, J., \& Pucillo, C. (2003). Oxidative stress stimulates IL-4 and IL-6 production in mast cells by an APE/Ref-1-dependent pathway. European journal of immunology, 33(8), 2168-2177.

[26] Kossmann, T., Hans, V., Imhof, H. G., Trentz, O., \& Morganti-Kossmann, M. C. (1996). Interleukin-6 released in human cerebrospinal fluid following traumatic brain injury may trigger nerve growth factor production in astrocytes. Brain research, 713(1), 143-152.

[27] Gruol, D. L., \& Nelson, T. E. (1997). Physiological and pathological roles of interleukin6 in the central nervous system. Molecular neurobiology, 15(3), 307-339.

[28] Lucas, S. M., Rothwell, N. J., \& Gibson, R. M. (2006). The role of inflammation in CNS injury and disease. British journal of pharmacology, 147(S1).

[29] Alhosaini, K., AlSharari, S., \& Hafez, M. M. (2016). Rutin ameliorates high cholesterol diet induced alteration in lipid profile Interleukin-3 (IL3) and Interleukin6 (IL6) and liver inflammation. The FASEB Journal, 30(1 Supplement), lb554-lb554.

[30] Liu, J., Li, X., Yue, Y., Li, J., He, T., \& He, Y. (2005). The inhibitory effect of quercetin on IL-6 production by LPS-stimulated neutrophils. Cell Mol Immunol, 2(6), 455-460.

[31] Buruiana, F. E., Solà, I., \& Alonso-Coello, P. (2008). Recombinant human interleukin 10 for induction of remission in Crohn's disease. Cochrane Database of Systematic Reviews, 11.

[32] Magalingam, K. B., Radhakrishnan, A., \& Haleagrahara, N. (2013). Rutin, a bioflavonoid antioxidant protects rat pheochromocytoma (PC-12) cells against 6-hydroxydopamine (6OHDA)-induced neurotoxicity. International journal of molecular medicine, 32(1), 235240.

[33] Magalingam, K. B., Radhakrishnan, A., \& Haleagrahara, N. (2014). Protective effects of flavonol isoquercitrin, against 6-hydroxy dopamine (6-OHDA)-induced toxicity in PC12 cells. BMC research notes, 7(1), 49.

[34] Yang, J., Guo, J., \& Yuan, J. (2008). In vitro antioxidant properties of rutin. LWT-Food Science and Technology, 41(6), 1060-1066.

[35] Li, Y., Yao, J., Han, C., Yang, J., Chaudhry, M. T., Wang, S., ... \& Yin, Y. (2016). Quercetin, inflammation and immunity. Nutrients, 8(3), 167.

[36] Kauss, T., Moynet, D., Rambert, J., Al-Kharrat, A., Brajot, S., Thiolat, D., ... \& Mossalayi, M. D. (2008). Rutoside decreases human macrophage-derived inflammatory mediators and improves clinical signs in adjuvant-induced arthritis. Arthritis research \& therapy, 10(1), R19.

[37] Hu, Q. H., Zhang, X., Pan, Y., Li, Y. C., \& Kong, L. D. (2012). Allopurinol, quercetin and rutin ameliorate renal NLRP3 inflammasome activation and lipid accumulation in fructose-fed rats. Biochemical pharmacology, 84(1), 113-125.

[38] Javed, H., Khan, M. M., Ahmad, A., Vaibhav, K., Ahmad, M. E., Khan, A., ... \& Safhi, M. M. (2012). Rutin prevents cognitive impairments by ameliorating oxidative stress and neuroinflammation in rat model of sporadic dementia of Alzheimer type. Neuroscience, 210, 340-352. 